\title{
Selective PDE4 inhibitors as potent anti-inflammatory drugs for the treatment of airway diseases
}

\author{
Vincent Lagente/ ${ }^{+}$, Corinne Martin-Chouly, Elisabeth Boichot, Marco A Martins*, \\ Patrica MR Silva*
}

\begin{abstract}
INSERM U620, Faculté de Pharmacie, Université de Rennes 1, 2, avenue du Professeur Léon Bernard, 35043 , Rennes Cedex, Rennes, France * Laboratório de Inflamação, Departamento de Fisiologia e Farmacodinâmica, Instituto Oswaldo Cruz-Fiocruz, Rio de Janeiro, RJ, Brasil
\end{abstract}

\begin{abstract}
Phosphodiesterases (PDEs) are responsible for the breakdown of intracellular cyclic nucleotides, from which PDE4 are the major cyclic AMP metabolizing isoenzymes found in inflammatory and immune cells. This generated greatest interest on PDE4 as a potential target to treat lung inflammatory diseases. For example, cigarette smokeinduced neutrophilia in BAL was dose and time dependently reduced by cilomilast. Beside the undesired side effects associated with the first generation of PDE4 inhibitors, the second generation of selective inhibitors such as cilomilast and roflumilast showed clinical efficacy in asthma and chronic obstrutive pulmonary diseases trials, thus re-enhancing the interest on these classes of compounds. However, the ability of PDE4 inhibitors to prevent or modulate the airway remodelling remains relatively unexplored. We demonstrated that selective PDE4 inhibitor RP 73-401 reduced matrix metalloproteinase (MMP)-9 activity and TGF- $\beta 1$ release during LPS-induced lung injury in mice and that CI-1044 inhibited the production of MMP-1 and MMP-2 from human lung fibroblasts stimulated by pro-inflammatory cytokines. Since inflammatory diseases of the bronchial airways are associated with destruction of normal tissue structure, our data suggest a therapeutic benefit for PDE4 inhibitors in tissue remodelling associated with chronic lung diseases.
\end{abstract}

Key words: phosphodiesterase type4 - inflammation - airway diseases

The selective targeting of phosphodiesterases type 4 (PDE4) has been actively pursued as a novel therapeutic approach in the treatment of respiratory diseases associated with inflammatory processes such as asthma and chronic obstructive pulmonary disease (COPD). The rationale for their use in respiratory disease is based on the clinical efficacy of non-selective PDE inhibitors such as theophylline, the detection of PDE4 in many of the cells involved in these diseases and the emergence of positive results from a number of pharmacological studies and clinical trials currently evaluating the efficacy of selective PDE4 inhibitors in respiratory diseases (Barnette 1999, Spina 2000). PDE4 represent the major class of PDE expressed in human inflammatory cells (Wang et al. 1999) and in particular in macrophages, eosinophils and neutrophils, the main cell types present in the lungs of asthmatic and COPD patients.

PDE4 are members of the phosphodiesterase (PDE) superfamily of enzymes, which comprises at least 11 members hydrolyzing cyclic AMP (adenosine 3',5' -cyclic monophosphate) and/or cyclic GMP (guanosine 3',5' -cyclic monophosphate) (Houslay et al. 1998, Conti \& Jin 1999, Giembycz 2000, 2001). In the case of PDE4, there are

Financial support: Conseil Régional de Bretagne, INSERM/ Fiocruz collaboration project, Faperj, $\mathrm{CNPq}$

${ }^{+}$Corresponding author. E-mail: vincent.lagente@univrennes1.fr

Received 8 November 2004

Accepted 30 December 2004 four gene products and multiple splice variants resulting in a variety of PDE4 isoforms. PDE4 selectively catalyse the hydrolysis of cAMP and the anti-inflammatory effects of selective PDE4 inhibitors were supposed to result of the reduction of cAMP hydrolysis. However, some recent studies have demonstrated that PDE4 could also act through cAMP-independent mechanisms. Indeed, we have observed that PDE4 inhibitors triggered a cAMP-independent inhibition of fMLP-induced $\mathrm{O}_{2}$ - release from bronchoalveolar lavage cells of rats exposed to lipopolysaccharide (Jacob et al. 2004). We also showed that the inhibitory effect of PDE4 inhibitors on $\mathrm{O}_{2}$ - production is mediated by the activation of $\mathrm{p} 44 / 42_{\text {MAPK }}$ and that PDE4 inhibit p44/42 ${ }_{\text {MAPK }}$ by a direct interaction (Jacob et al. 2004). This study allowed us to identify a novel mechanism involving MAPK in the pathway connecting PDE4 to fMLP-induced $\mathrm{O}_{2}$ - generation in neutrophils.

\section{Therapeutical potential of selective PDE4 inhibitors}

During last decade, numerous studies have demonstrated the modulation of inflammatory cells activation by selective PDE4 inhibitors. It is now established that an elevation of cAMP is able to inhibit some of inflammatory processes. The use of PDE4 inhibitors, preventing cAMP hydrolysis, appears obvious to treat inflammatory diseases like asthma and COPD.

Rolipram, a first generation selective PDE4 inhibitor, has been shown to decrease influx of inflammatory cells to the site of inflammation induced by various stimuli (Lagente et al. 1994,1995, Teixeira et al. 1997). In vitro exposure of rat eosinophils to rolipram decreases eosinophil migration evoked by either PAF or $\mathrm{LTB}_{4}$ (Alves et al. 1996). It has also been demonstrated that salbutamol it- 
self did not modify eosinophil migration evoked by either PAF or eotaxin in vitro but clearly improved the inhibitory effect of rolipram suggesting an involvement of the cAMP pathway in the eosinophil chemotaxis (Silva et al. 2001). In a guinea pig model of lipopolysaccharide (LPS)-induced lung neutrophilia, rolipram was able to inhibit $63 \%$ of neutrophil infiltration (Toward \& Broadley 2001), could completely abolish neutrophil influx induced by antigen challenge in Brown Norway rats (Howell et al. 1995) and could decrease by $75 \%$ LPS-induced lung neutrophilia in mice (Miotla et al. 1998). In a recent study, we compared the effect of a selective PDE4 inhibitor, cilomilast and a glucocorticoid, dexamethasone on cigarette smoke and LPS induce airway neutrophilia (Leclerc et al. 2004). As expected both cilomilast and dexamethasone were able to dosedependently block LPS-induced neutrophilia. Cilomilast was also able to block neutrophilia induced by cigarette smoke with the same efficacy. However, dexamethasone treatment at the same dose was unable to block neutrophilia induced by cigarette smoke exposure (Leclerc et al. 2004). Furthermore, the selective PDE4 inhibitor, CI-1044 given orally $(30 \mathrm{mg} / \mathrm{kg} / \mathrm{day})$, significantly inhibited the development of emphysema by $89 \%, 24$ weeks following cigarette smoke exposure in mice (Pruniaux et al. 2003) and support the use of PDE4 in-hibitors as a new COPD therapy.

One of the major anti-inflammatory effect of PDE4 inhibitors is their ability to down-regulate cytokine production both in vivo and in vitro. In vivo, some studies report the ability of PDE4 inhibitors to reduce TNF- $\alpha$ release in the blood or in BAL fluids of various species (Griswold et al. 1998, Corbel et al. 2002a). In vitro, several selective PDE4 inhibitors, including rolipram and cilomilast, have been previously shown to inhibit the release of TNF- $\alpha$ by LPS-stimulated murine mononuclear cells, human monocytes or whole blood from healthy individuals (Souness et al. 1996, Gonçalves de Moraes et al. 1998). Furthermore, we recently showed that rolipram and cilomilast inhibit LPS-stimulated TNF- $\alpha$ production in the whole blood from patients with COPD (Ouaged et al. 2004). The novel PDE4 inhibitor CI-1044 which induced a potent inhibition of PDE4 activity both in vitro and in vivo (Burnouf et al. 2000), is 2 to 10 times more potent than rolipram and cilomilast respectively, to inhibit LPSstimulated TNF- $\alpha$ release in the human whole blood from patients with COPD.

Nevertheless, the ability of PDE4 inhibitors to prevent or modulate the airway remodelling remains a relatively unexplored area. Matrix metalloproteinases (MMPs) play an important role in the proteolytic degradation of the extracellular matrix (ECM), both in physiological processes and during pathological events (Corbel et al. 2002b). The most accepted theory for the pathogenesis of COPD, which includes emphysema and/or chronic bronchitis, and idiopathic pulmonary fibrosis (IPF), involves deteriorated lung homeostasis. This abnormal remodelling results in a net increase in deposited ECM and collagen content in lungs, resulting from MMPs/TIMPs imbalance (Jeffery 2001). These lung disorders are also characterized by a striking fibroblast/myofibroblast proliferation and activation, which increase the production of matrix-degrading enzymes (Crouch 1990, Segura-Valdez et al. 2000). Furthermore, local over-expression of cytokines and/or growth factor stimulates resident lung fibroblasts to synthesize increased amount of collagen and different MMPs such as collagenase-1 (MMP-1), gelatinases A and B (MMP-2 and MMP-9) (Sasaki et al. 2000, Zhu et al. 2001).

However, we reported that the selective PDE4 inhibitor, piclamilast reduced antigen challenge induced-cell recruitment in airways of sensitized mice, but also diminished gelatinase B MMP -9 (Belleguic et al. 2000). We have also demonstrated that piclamilast (RP 73-401), reduced MMP-9 activity and TGF- $\beta 1$ release during acute lung injury in mice, suggesting that PDE4 inhibitors might modulate tissue remodelling associated with lung injury (Corbel et al. 2002a). Furthermore recent studies have shown that two selective PDE4 inhibitors, cilomilast and rolipram, inhibited fibroblast chemotaxis and fibroblastmediated collagen gel contraction. It has also been demonstrated that cilomilast might inhibit the TNF- $\alpha$ induced release of both MMP-1 and MMP-9 from HFL-1 (Kohyama et al. 2002a,b). Fibroblasts cultured with PMA or TNF- $\alpha$ released increased amounts of pro-MMP-1, whereas TGF- $\beta 1$ had no effect (Martin-Chouly et al. 2004). Incubation with CI-1044 or cilomilast significantly prevented the TNF- $\alpha$ increase in pro-MMP-1. These results suggest that PDE4 inhibitors are effective in inhibiting the pro-MMP-2 and pro-MMP-1 secretion induced by TNF- $\alpha$ and might underline a potential therapeutic benefit of selective PDE4 inhibitors in lung diseases associated with abnormal tissue remodelling (Martin-Chouly et al. 2004).

\section{Clinical experience with selective PDE4 inhibitors}

The most advanced PDE4 inhibitors in clinical development i.e., cilomilast and roflumilast have demonstrated encouraging efficacy to date. Cilomilast has been shown to improve both pulmonary function and symptoms of COPD in 424 patients with moderate-to-severe disease, producing significant improvements in FEV1, FVC and PEFR versus placebo over 6 weeks (Compton et al. 2001). In addition, consistent improvements in patient quality of life approaching that defined as clinically relevant were observed compared with placebo (Giembycz 2001, Compton et al. 2001). In addition, cilomilast significantly reduces the risk of exacerbations and provides sustained improvements in lung function over 6 months in patients with mild-to moderate disease (Edelson 2001). Interestingly, the improvements in lung function observed with cilomilast are independent of smoking status (Zhu et al. 2002). More recently, the anti-inflammatory effects of cilomilast observed in preclinical studies have been confirmed in a small, randomized, placebo-controlled trial of 59 patients with COPD (Gamble et al. 2003). After 12 weeks of cilomilast therapy, bronchial biopsies taken from treated patients indicated that cilomilast significantly reduces levels of inflammatory markers, i.e. CD8 T cells and CD68 macrophages (Gamble et al. 2003). Roflumilast has also shown encouraging efficacy in patients with COPD, with significant improvements observed in FEV1 and PEFR versus baseline (Leitchl et al. 2002).

A major benefit of cilomilast and roflumilast is their 
superior safety and tolerability profile versus theophylline and the first generation PDE4 inhibitors. Indeed, theophylline is associated with serious cardiovascular and central nervous system side effects, even at therapeutic doses. These effects are generally attributed to nonselective inhibition of PDEs, as well as concomitant adenosine receptor antagonism and include tachycardia and serious arrhythmias, focal and generalized seizures, and coma (Barnes 2003). When the first generation PDE4 inhibitors were developed, it was hypothesized that these compounds could present less side effects than theophylline, due to their selectivity for PDE4. However, these agents were associated with a number of adverse events, including nausea, vomiting and gastric acid secretion, which limit their clinical use (Barnette 1999). In contrast, second generation PDE4 inhibitors have an improved therapeutic ratio. Cilomilast has proven safe and well tolerated at doses of up to $15 \mathrm{mg}$ in both short- and long-term dosing trials, with a moderate incidence of adverse events which appears in more than $5 \%$ of patients (Giembycz 2001, Compton et al. 2001). The most common adverse experience was nausea, which arose most often in the cilomilast 10 and $15 \mathrm{mg}$ treatment groups. Nausea arose most commonly within a few days of starting treatment and was generally mild or moderate and selflimiting. Vomiting was infrequent in all treatment groups. The most common serious adverse event was exacerbation of COPD, which was responsible for all three cases in the placebo group. There was no pattern or trend for any serious adverse reactions associated with cilomilast.

\section{Strategies to avoid side-effects induced by oral PDE4 inhibitors}

The therapeutic promise of PDE4 inhibitors has been tempered by their significant side-effects, particularly nausea and emesis. Thus the broad goal of drug development has been to improve the side-effect profile of PDE4 inhibitors while maintaining or improving efficacy. One strategy that has been pursued with some success is based upon the observation that PDE4 enzymes exist in both low- and high-affinity rolipram-binding conformations (Torphy et al. 1992a, Jacobitz et al. 1996). Although inhibition of the low-affinity rolipram-binding conformation correlates with inhibition of cyclic AMP hydrolysis and with inhibition of several inflammatory cell functions, inhibition of high-affinity rolipram binding appears to correlate with the production of certain side effects (Barnette et al. 1996, Souness et al. 1997). This has been demonstrated with a selective PDE4 inhibitor derived from 9-benzyladenine (NCS 613), which elicited anti-inflammatory properties (Boichot et al. 2000). The fact that NCS 613 did not stimulate the gastric acid secretion suggest that this compound structurally unrelated to rolipram, may produce fewer gastrointestinal side effects (Boichot et al. 2000).

Compounds with relative selectivity for the lowaffinity form of the enzyme would therefore be expected to display better therapeutic ratios than rolipram, which is selective for the high affinity conformation (Barnette et al. 1996).

A second promising strategy is the development of subtype selective PDE4 Inhibitors. Indeed, type 4 phosphodiesterases consist of 4 subtypes A, B, C and D, en- coded by 4 genes (Conti \& Jin 1999), which are alternatively spliced in different variants $1,2,3(2,3,4,5,6)$. Two different structures of these variants can be distinguished, short forms $(65-75 \mathrm{kDa})$ and long forms (80$130 \mathrm{kDa})$. The difference between short and long forms lies in the N-terminal region, at the level of UCR1 and UCR2 (upstream conserved regions): short forms are truncated at UCR2 and long forms have both UCR1 and UCR2 (Bolger et al. 1997). The different PDE4 subtypes are differently expressed depending on the tissue. PDE4A is expressed in all tissues except in neutrophils (Wang et al. 1999), PDE4B is widely expressed and is the pre-dominant PDE4 subtype in monocytes and neutrophils (Wang et al. 1999), but lacks in cortex and epithelial cells (Jin et al. 1998), PDE4C is absent from circulating inflammatory cells, cortex and hippocampus and has been detected in lung and testis (Obernolte et al. 1997, Manning et al. 1999, Martin-Chouly et al. 2004) and PDE4D is particularly active in lung, cortex, cerebellum and T cells (Erdogan \& Houslay 1997, Jin et al. 1998). The up-regulations of the PDE4B subtype in response to pro-inflammatory agents suggest that PDE4B could be particularly involved in inflammatory processes. However, by screening a large number of PDE4 inhibitors against the recombinant human enzyme, it has been able to identify a few selective subtype inhibitors (Manning et al. 1999). The results obtained using these kinds of compounds suggest that PDE4A and or PDE4B may play the major role in regulating LPS-induced TNF- $\alpha$ release and T-cell proliferation but do not rule out PDE4D as an important mediator of other activities in mononuclear leukocytes and other immune and inflammatory cells (Manning et al. 1999, Jin \& Conti 2002). Using an in vitro model of DMSO-treated HL60 cells, we found a change of PDE4 subtype profile during differentiation (Jacob et al. 2002). PDE4B was the predominant isoenzyme, PDE4D was down-regulated and PDE4A was no longer detectable. Additionally, the more NADPH oxidase was activated by PMA, the less PDE4A was expressed, suggesting that NADPH oxidase activity could be used as a surrogate marker of PDE4A down-regulation. Rolipram and Ariflo (cilomilast), two selective PDE4 inhibitors, dose-dependently inhibited receptor-coupled activation of superoxide. These results suggest that PDE4B is the main subtype involved in regulating superoxide induced by immune complex activation. Furthermore, these cells, expressing almost exclusively PDE4B subtype, could be useful to identify selective PDE4B inhibitors (Jacob et al. 2002).

More recently, using mice deficient in either the PDE4B or PDE4D gene, Robichaud and colleagues (2002) provide evidence that emesis resulting from administration of PDE4 inhibitors is due to the selective inhibition of PDE4D. This is an unfortunate finding because the most clinically advanced PDE4 inhibitors are selective for PDE4D.

\section{Conclusion}

Type 4 phosphodiesterases have the potency to modulate a large range of inflammatory mediators release through cAMP-dependent and cAMP-independent mechanisms. Several times, PDE4B subtype has been 
shown to be particularly involved in these inflammatory processes, indicating that this PDE4B subtype could be a good target for new anti-inflammatory compounds with less side effects than already known non-subtype selective PDE4 inhibitors. These side effects, mainly nausea and emesis, considerably limit the use of these drugs. PDE4 inhibitors are very promising compounds, which could bring new alternatives for the treatment of chronic diseases like asthma, chronic obstructive pulmonary disease and atopic dermatitis.

\section{REFERENCES}

Alves AC, Pires ALA, Cruz HN, Serra MF, Diaz BL, Cordeiro RSB, Lagente V, Martins MA, Silva PMR 1996. Selective inhibition of phosphodiesterase type IV suppresses the chemotactic responsiveness of rat eosinophils in vitro. Eur J Pharmacol 312: 89-96.

Barnes PJ 2003. Theophylline: new perspectives for an old drug. Am J Respir Crit Care Med 67: 813-818.

Barnette MS 1999. Phosphodiesterase 4 (PDE4) inhibitors in asthma and chronic obstructive pulmonary disease (COPD). Prog Drug Res 53: 193-229.

Barnette MS, Bartus JO, Burman M, Christensen SB, Cieslinski LB, Esser KM, Prabhakar US, Rush JA, Torphy TJ 1996. Association of the anti-inflammatory activity of phosphodiesterase 4 (PDE4) inhibitors with either inhibition of PDE4 catalytic activity or competition for $[3 \mathrm{H}]$ rolipram binding. Biochem Pharmacol 51: 949-956.

Belleguic C, Corbel M, Germain N, Boichot E, Delaval P, Lagente V 2000. Reduction of matrix metalloproteinase-9 activity by the selective phosphodiesterase 4 inhibitor, RP 73-401 in sensitized mice. Eur J Pharmacol 404: 369-373.

Boichot E, Wallace JL, Germain N, Corbel M, Lugnier C, Lagente V, Bourguignon JJ 2000. Anti-inflammatory activities of a new series of selective phosphodiesterase 4 inhibitors derived from 9-benzyladenine. J Pharmacol Exp Ther 292: 647-653.

Bolger GB, Erdogan S, Jones RE, Loughney K, Scotland G, Hoffmann R, Wilkinson I, Farrell C, Houslay MD 1997. Characterization of five different proteins produced by alternatively spliced mRNAs from the human cAMP-specific phosphodiesterase PDE4D gene. Biochem J 328: 539548.

Burnouf C, Auclair E, Avenel N, Bertin B, Bigot C, Calvet A, Chan K, Durand C, Fasquelle V, Féru F, Gilbersten R, Jacobelli H, Kebsi A, Lallier E, Maignel J, Martin B, Milano S, Ouagued M, Pascal Y, Pruniaux M-P, Puaud J, Rocher M-N, Terrasse C, Wrigglesworth R, Doherty AM 2000. Synthesis, structure-activity relationships, and pharmacological profile of 9-amino-4-oxo-1-phenyl-3,4,6,7tetrahydrol[1,4]diazepino[6,7,1-hi]indoles: discovery of potent, selective phosphodiesterase type 4 inhibitors. $J$ Med Chem 43: 4850-4867.

Compton CH, Gubb J, Nieman R, Edelson J, Amit O, Bakst A, Ayres JG, Creemers JP, Schultze-Werninghaus G, Brambilla C, Barnes NC, International Study Group 2001. Cilomilast, a selective phosphodiesterase-4 inhibitor for treatment of patients with chronic obstructive pulmonary disease: a randomised, dose-ranging study. Lancet 358: 265-270.

Conti M, Jin SL 1999.The molecular biology of cyclic nucle- otide phosphodiesterases. Prog Nucleic Acid Res Mol Biol 63: $1-38$.

Corbel M, Germain N, Lanchou J, Molet S, R e Silva PM, Martins MA, Boichot E, Lagente V 2002a. The selective phosphodiesterase 4 inhibitor RP 73-401 reduced matrix metalloproteinase 9 activity and transforming growth factor-beta release during acute lung injury in mice: the role of the balance between Tumor necrosis factor-alpha and interleukin-10. J Pharmacol Exp Ther 301: 258-265.

Corbel M, Belleguic C, Boichot E, Lagente V 2002b. Involvement of gelatinases (MMP-2 and MMP-9) in the development of airway inflammation and pulmonary fibrosis. Cell Biol Tox 18: 51-61.

Crouch E 1990. Pathobiology of pulmonary fibrosis. Am J Lung Cell Mol Physiol 259: L159-L184.

Edelson JD, Compton C, Nieman R 2001. Cilomilast (Ariflo), a potent, selective inhibitor of phosphodiesterase 4, improves lung function in COPD patients: results of a 6-month trial. Am J Respir Crit Care Med 163: A277.

Erdogan S, Houslay MD 1997. Challenge of human Jurkat Tcells with the adenylate cyclase activator forskolin elicits major changes in cAMP phosphodiesterase (PDE) expression by up-regulating PDE3 and inducing PDE4D1 and PDE4D2 splice variants as well as down-regulating a novel PDE4A splice variant. Biochem J 321: 165-175.

Gamble E, Grootendorst DC, Brightling CE, Troy S, Qiu Y, Zhu J, Parker D, Matin D, Majumdar S, Vignola AM, Kroegel C, Morell F, Hansel TT, Rennard SI, Compton C, Amit O, Tat T, Edelson J, Pavord ID, Rabe KF, Barnes NC, Jeffery PK 2003. Antiinflammatory effects of the phosphodiesterase-4 inhibitor cilomilast (Ariflo) in chronic obstructive pulmonary disease. Am J Respir Crit Care Med 168: 976-982.

Giembycz MA 2000. Phosphodiesterase 4 inhibitors and the treatment of asthma: where are we now and where do we go from here? Drugs 59: 193-212.

Giembycz MA 2001. Cilomilast: a second generation phosphodiesterase 4 inhibitor for asthma and chronic obstructive pulmonary disease. Expert Opin Investig Drugs 10: 1361-1379.

Gonçalves de Moraes VL, Singer M, Vargaftig BB, Chignard M 1998. Effects of rolipram on cyclic AMP levels in alveolar macrophages and lipopolysaccharide-induced inflammation in mouse lung. Br J Pharmacol 123: 631-636.

Griswold DE, Webb EF, Badger AM, Gorycki PD, Levandoski PA, Barnette MA, Grous M, Christensen S, Torphy TJ 1998. SB 207499 (Ariflo), a second generation phosphodiesterase 4 inhibitor, reduces tumor necrosis factor alpha and interleukin-4 production in vivo. J Pharmacol Exp Ther 287: 705-711.

Houslay MD, Sullivan M, Bolger GB 1998. The multienzyme PDE4 cyclic adenosine monophosphate-specific phosphodiesterase family: intracellular targeting, regulation, and selective inhibition by compounds exerting anti-inflammatory and antidepressant actions. Adv Pharmacol 44: 225342.

Howell RE, Jenkins LP, Fielding LE, Grimes D 1995. Inhibition of antigen-induced pulmonary eosinophilia and neutrophilia by selective inhibitors of phosphodiesterase types 3 or 4 in 
Brown Norway rats. Pulm Pharmacol 8: 83-89.

Jacob C, Leport M, Szilagyi C, Allen JM, Bertrand C, Lagente V 2002. DMSO-treated HL60 cells: a model of neutrophillike cells mainly expressing PDE4B subtype. Int Immunopharmacol 2: 1647-1656.

Jacob C, Szilagyi C, Allen JM, Bertrand C, Lagente V 2004. Role of PDE4 in superoxide anion generation through p44/ 42MAPK regulation: a cAMP and a PKA-independent mechanism. Br J Pharmacol 143: 257-268.

Jacobitz S, McLaughlin MM, Livi GP, Burman M, Torphy TJ 1996. Mapping the functional domains of human recombinant phosphodiesterase 4A: structural requirements for catalytic activity and rolipram binding. Mol Pharmacol 50: 891-899.

Jeffery PK 2001. Remodeling in asthma and chronic obstructive lung disease. Am J Respir Care Med 164 : S28-S38.

Jin SLC, Conti M 2002. Induction of the cyclic nucleotide phosphodiesterase PDE4B is essential for LPS-activated TNF$\alpha$ responses. PNAS 99: 7628-7633.

Jin SL, Bushnik T, Lan L, Conti M 1998. Subcellular localization of rolipram-sensitive, cAMP-specific phosphodiesterases. Differential targeting and activation of the splicing variants derived from the PDE4D gene. $J$ Biol Chem 273: 19672-19678.

Kohyama T, Liu X, Wen FQ, Zhu YK, Wang H, Kim HJ, Takizawa H, Cieslinski LB, Barnette MS, Rennard SI 2002a. PDE4 inhibitors attenuate fibroblast chemotaxis and contraction of native collagen gels. Am J Respir Cell Mol Biol 26: 694-701.

Kohyama T, Liu X, Zhu YK, Wen FQ, Wang H, Fang Q, Kobayashi T, Rennard SI 2002b. Phosphodiesterase 4 inhibitors cilomilast inhibits fibroblast-mediated collagen gel degradation induced by tumor necrosis factor- $\alpha$ and neutrophil elastases. Am J Respir Cell Mol Biol 27: 487-494.

Lagente V, Moodley I, Perrin S, Mottin G, Junien JL 1994. Effects of isozyme-selective phosphodiesterase inhibitors on eosinophil infiltration in the guinea-pig lung. Eur $J$ Pharmacol 255: 253-256.

Lagente V, Pruniaux MP, Junien JL, Moodley I 1995. Modulation of cytokine-induced eosinophil infiltration by phosphodiesterase inhibitors. Am J Respir Crit Care Med 151: $1720-1724$.

Leclerc O, Planquois JM, Lagente V, Berthelier C, Artola M, Carré C, Eichholtz T, Bertrand C, Schmidlin F 2004. A model of cigarette smoke-induced COPD inflammation in mice: steroid-insensitive but PDE4 sensitive. International Meeting on Nitric Oxide, Cytokines and Inflammation, Rio de Janeiro, Brazil.

Leitchl S, Syed J, Bredenbroker D 2002. Efficacy of oncedaily roflumilast, a new, orally active, selective phosphodiesterase 4 inhibitor, in chronic obstructive pulmonary disease. Am J Respir Crit Care Med 165: A229.

Manning CD, Burman M, Christensen SB, Cieslinski LB, Essayan DM, Grous M, Torphy TJ, Barnette MS 1999. Suppression of human inflammatory cell function by subtype-selective PDE4 inhibitors correlates with inhibition of PDE4A and PDE4B. Br J Pharmacol 128: 1393-1398.

Martin-Chouly CA, Astier A, Jacob C, Pruniaux MP, Bertrand
C, Lagente V 2004. Modulation of matrix metalloproteinase production from human lung fibroblasts by type 4 phosphodiesterase inhibitors. Life Sci 75: 823-840.

Miotla JM, Teixeira MM, Hellewell PG 1998. Suppression of acute lung injury in mice by an inhibitor of phosphodiesterase type 4. Am J Respir Cell Mol Biol 18: 411-420.

Obernolte R, Ratzliff J, Baecker PA, Daniels DV, Zuppan P, Jarnagin K, Shelton ER 1997. Multiple splice variants of phosphodiesterase PDE4C cloned from human lung and testis. Biochim Biophys Acta 1353: 287-297.

Ouaged M, Martin-Chouly CAE, Leportier C, Belleguic C, Delaval P, Lagente V, Danzin C, Bertrand C Pruniaux MP 2002. The novel phosphodiesterase 4 inhibitor CI-1044 inhibits in vitro LPS-induced TNF-alpha production in whole blood of COPD patients. Fund Clin Pharmacol 16: 369.

Pruniaux MP, Xu J, Bertrand CP, Shapiro SD 2003. Efficacy of a selective phosphodiesterase 4 inhibitor, CI-1044, on cigarette smoke-induced emphysema development in mice. Am J Respir Cell Mol Biol 167: A874.

Robichaud A, Stamatiou PB, Jin C, Lachance N, MacDonald D, Laliberté F, Liu S, Huang Z, Conti M, Chan CC 2002. Deletion of phosphodiesterase 4D in mice shortens alpha2adrenoceptor-mediated anesthesia, a behavioural correlate of emesis. J Clin Invest 110: 1045-1052.

Sasaki M, Kashima M, Ito T, Watanabe A, Izumiyama N, Sano M, Kagaya M, Shioya T, Miura M 2000. Differential regulation of metalloproteinases production proliferation and chemotaxis of human lung fibroblasts by PDGF, interleukin$1 \beta$ and TNF $\alpha$. Mediators Inflam 9: 155-160.

Segura-Valdez L, Pardo A, Gaxiola M, Uhal BD, Becerril C, Selman M 2000. Upregulation of gelatinases A and B, collagenases 1 and 2, and increased parenchymal cell death in COPD. Chest 117: 684-694.

Silva PMR, Alves AC, Serra MF, Pires AL, Silva JP, Barreto EO, Cordeiro RSB, Jose PJ, Teixeira MM, Lagente V, Martins MA 2001. Modulation of eotaxin formation and eosinophil migration by selective inhibitors of phosphodiesterase type 4 isoenzyme. Br J Pharmacol 134: 283-294.

Souness JE, Griffin M, Maslen C, Ebsworth K, Scott LC, Pollock K, Palfreyman MN, Karlsson JA 1996. Evidence that cyclic AMP phosphodiesterase inhibitors suppress TNF alpha generation from human monocytes by interacting with a 'low-affinity' phosphodiesterase 4 conformer. $\mathrm{Br} J$ Pharmacol 118: 649-658.

Souness JE, Rao S 1997. Proposal for pharmacologically distinct conformers of PDE4 cyclic AMP phosphodiesterases. Cell Signal 9: 227-236.

Spina D 2000. The potential of PDE4 inhibitors in asthma or COPD. Curr Opin Investig Drugs 1: 204-213.

Teixeira MM, Gristwood RW, Cooper N, Hellewell PG 1997. Phosphodiesterase (PDE)4 inhibitors: anti-inflammatory drugs of the future? Trends Pharmacol Sci 18:164-171.

Torphy TJ, Stadel JM, Burman M, Cieslinski LB, McLaughlin MM, White JR, Livi GP 1992. Coexpression of human cAMP-specific phosphodiesterase activity and high affinity rolipram binding in yeast. J Biol Chem 267: 1798-1804. 
Toward TJ, Broadley KJ 2001. Chronic lipopolysaccharide exposure on airway function, cell infiltration, and nitric oxide generation in conscious guinea pigs: effect of rolipram and dexamethasone. J Pharmacol Exp Ther 298: 298-306.

Wang P, Wu P, Ohleth KM, Egan RW, Billah MM 1999. Phosphodiesterase $4 \mathrm{~B} 2$ is the predominant phosphodiesterase species and undergoes differential regulation of gene expression in human monocytes and neutrophils. Mol Pharmacol 56: 170-174.
Zhu J, Anderson K, Vleisides T 2002. The positive effect of cilomilast on lung function in patients with chronic obstructive pulmonary disease (COPD) is independent of patient smoking status. Eur Respir J 20: 620s.

Zhu YK, Liu XD, Skold CM, Umino T, Wang HJ, Spurzem JR, Kohyama T, Ertl RF, Rennard SI 2001. Synergistic neutrophil elastase-cytokine interaction degrades collagen in threedimensional culture. Am J Physiol Lung Cell Mol Physiol 281: L868-878. 